\title{
A CONSTITUIÇÃO SUBJETIVA E SAÚDE MENTAL: CONTRIBUIÇÕES WINNICOTTIANAS
}

Heloisa Aguetoni Cambuí, Carmen Maria Bueno Neme e Jorge Luís Ferreira Abrão

\author{
Heloisa Aguetoni \\ Cambuí \\ Universidade \\ Estadual Paulista \\ Júlio de Mesquita \\ Filho, Faculdade de \\ Ciências de Bauru. \\ Carmen Maria Bueno \\ Neme \\ Universidade \\ Estadual Paulista \\ Júlio de Mesquita \\ Filho, Faculdade de \\ Ciências de Bauru. \\ Jorge Luís Ferreira Abrão \\ Universidade \\ Estadual Paulista \\ Júlio de Mesquita \\ Filho, Faculdade de \\ Ciências e Letras \\ de Assis.
}

RESUMO: Perante o sofrimento emocional observado na clínica psicanalítica contemporânea, pretende-se discutir as implicações das relações inter-humanas iniciais para a constituição subjetiva. Sob o referencial psicanalítico winnicottiano, apresentam-se reflexões que contemplam as dimensões de saúde psíquica e adoecimento a partir de uma perspectiva psicopatológica relacional. O sofrimento psíquico aqui referido se origina de possíveis experiências traumáticas no bojo da relação mãe-bebê, que podem levar o indivíduo a uma vivência confusa, ou, ainda, à impossibilidade de gestar seu próprio nascimento psíquico. Conclui-se que o paradigma winnicottiano contribuiu de forma original para o campo da saúde mental possibilitando manejos clínicos diferenciados.

Palavras-chave: Relação mãe-bebê, constituição psíquica, Winnicott, sofrimento psíquico, saúde mental.

ABSTRACT: Subjective constitution and mental health: Winnicott's contributions. Towards the emotional suffering observed in contemporary psychoanalytic practice, this article discusses the implications of initial inter-human relationships for the subjective constitution. Based on Winnicott's psychoanalytic references, the paper presents some reflections that contemplate the dimensions of mental health and illness from a relational psychopathological perspective. The psychic suffering discussed arises from possible traumatic experiences in the midst of the mother-infant relationship, which may lead the individual to a confusing experience, or even to the impossibility of gestating his/her own psychic birth. The conclusion is that the Winnicott's paradigm has contributed in an original way to the field of mental health, enabling differential clinical managements.

Keywords: Mother-infant relationship; psychic constitution; Winnicott; psychic suffering; mental health.

DOI - http://dx.doi.org/10.1590/S1516-14982016000100009 
A s profundas transformações sócio-históricas pelas quais atravessa o mundo incidem inevitavelmente sobre o campo das subjetividades, cujo impacto acarreta novas formas de subjetivação, modalidades de sofrimento psíquico e demandas clínicas. A compreensão quanto ao surgimento desses novos quadros, que constituem parcela significativa da demanda contemporânea, pode ser buscada no âmbito das relações vinculares iniciais, na medida em que as macrotransformações contemporâneas refletem-se nos modos de relação inter-humanas, de forma especial, nas relações inicias mãe-bebê, fundamentais para a constituição psíquica do sujeito.

A teoria psicanalítica propõe que a constituição da saúde psíquica se estabelece a partir da qualidade da inter-relação inicial entre a mãe e o bebê. O sofrimento emocional manifestado na atualidade revela a fragilidade da constituição e sustentação psíquica, decorrente da instabilidade e da ruptura das relações vinculares, principalmente nos períodos iniciais da vida. Considera-se pertinente a busca por reflexões que interroguem as ressonâncias das primeiras experiências relacionais do bebê com o meio que o circunscreve, uma vez que, esse possui papel essencial na formação da saúde mental.

Ao abordar essas experiências, Zornig (2000), afirma que "a relação mãe-bebê opera sobre um universo de grande complexidade, que começa com o equipamento material com o qual a criança vem ao mundo e termina no entorno social em que mãe e bebê encontram-se mergulhados” (p.27). Em sua trajetória, Zornig discorre sobre a importância da observação direta de crianças, como via de compreensão da constituição de adultos saudáveis, procedentes de uma infância normal.

Ao ressaltar a necessidade da presença das figuras parentais para que o sujeito possa se constituir, a concepção psicanalítica referente à constituição psíquica, perpassa, indubitavelmente, o campo da intersubjetividade. Esse encontro genuíno admite a possibilidade do acontecer humano e inaugura a experiência relacional. A aproximação entre um “outro”, constituído por experiências subjetivas individuais advindas de seu próprio processo de amadurecimento, e as potencialidades nucleares do vir a ser do bebê, "faz com que o eu da criança se torne viável" (KHAN, 1978, p.40).

Para Lisondo (2004), a origem, a estruturação e a constituição da subjetividade individual ocorrem no contexto da intersubjetividade. A concepção de intersubjetividade comporta um campo vincular inter-humano, o qual legitima ao indivíduo a possibilidade de morada no mundo e o compartilhamento de um sentido de realidade e de ser (LESCOVAR, 2008). "O acontecer humano demanda a presença de um outro. As primeiras organizações psíquicas do bebê, a entrada na temporalidade, a abertura da dimensão espacial e a personalização, 
só se constituem e ganham realização pela presença de alguém significativo (SAFRA, 2005, p.147).

A conjetura psicanalítica que, de forma interdependente, atrela a constituição subjetiva às experiências interacionais intersubjetivas, é discutida com excelência por Ogden (1996). Conforme o autor, "o sujeito não pode criar a si-mesmo; o desenvolvimento da subjetividade requer experiências de formas específicas de intersubjetividade" (p.55). Dessa forma, a apropriação pelo bebê do espaço intersubjetivo é mediada por eventos psicológicos que envolvem a díade mãe-bebê.

Segundo Winnicott (1960/1983), a concepção da origem do si-mesmo reside na experiência inicial do encontro inter-relacional humano. Assim, para que o bebê inaugure sua própria constituição, é necessária a presença afetiva e constante de outro, que acolha seu gesto primitivo e espontâneo de vir a ser no mundo, sendo esse gesto constitutivo intrínseco à condição humana. Winnicott (1968/2002) afirma que a base para a constituição psíquica do ser humano ocorre nos primórdios do relacionamento mãe-bebê. Nesse período, a mãe não é percebida pelo bebê como um sujeito à parte, mas sentida como extensão do seu próprio corpo. A teoria psicanalítica de Winnicott propõe que todo ser humano possui uma tendência inata ao amadurecimento emocional, ou seja, o bebê possui um potencial vital próprio que o impulsiona ao processo de desenvolvimento em busca do início de sua existência e, por consequência, de sua continuidade de ser. Embora Winnicott postule uma tendência inata ao amadurecimento, como algo essencial, da ordem do ser, ele também ressalta a relevância da existência concreta na constituição humana. De acordo com Winnicott (1963b/1994), "somente a partir da não-existência é que a existência pode começar” (p.76). Assim, a possibilidade de ser e, consequentemente, de sua continuidade de ser ocorre a partir do não-existir, no intervalo entre a não-existência e a existência (SANTOS, 2006).

Para que esse potencial inato se concretize é, portanto, fundamental a presença de um ambiente constante e facilitador, constituído pelos cuidados maternos e pelo meio em que o bebê se desenvolve (WINNICOTT, 1960/1983). Desse modo, a capacidade de ter uma existência pessoal, para que assim se inicie a possibilidade de constituição da continuidade de ser está relacionada aos cuidados ambientais ofertados ao lactente. O trajeto individual de subjetivação se dá por meio dos enlaces do bebê com seu cuidador. O desenvolvimento emocional comporta uma perspectiva tridimensional interdependente, na qual: "em um extremo há a hereditariedade; no outro extremo há o ambiente que apoia ou falha e traumatiza; e no meio está o indivíduo vivendo, se defendendo e crescendo" (WINNICOTT, 1959-1964/1983, p.125). 


\section{A EXPERIÊNCIA DE MUTUALIDADE NA INTIMIDADE DO RELACIONAMENTO MÃE-BEBÊ}

Os teóricos psicanalíticos da atualidade declaram um plausível consenso sobre a complexidade psicológica inerente ao bebê, envolvida em delicadas tessituras relacionais com a figura materna (OGDEN, 1996). Ainda conforme o autor, desde os momentos iniciais de vida, o bebê possui recursos vitais rudimentares, apresentando uma constituição particular, tendências inatas ao desenvolvimento, elementos sensórios e de motilidade e instintos associados ao desenrolar de seu desenvolvimento (WINNICOTT, 1956/2000), que permite a ele perceber e se comunicar de forma recíproca com a figura materna. Esta, por sua vez, ao vivenciar as necessidades do bebê como próprias, possibilita que sua subjetividade ceda lugar à do bebê, preservando, contudo, parte de sua própria subjetividade a fim de interpretar as experiências do lactente.

Mãe e criança vivem a experiência juntos, "não simplesmente ao mesmo tempo, mas enquanto experimentam e respondem, uma à outra, aos atos separados de estarem vivas vivendo a experiência" (OGDEN, 2002, p.749). Dessa forma, ambos se lançam ao encontro relacional, compartilham e experienciam essa vivência inaugural. Ressalta-se, entretanto, que a dimensão interna da experiência não é inata, mas conquistada pelo bebê, de forma paulatina, por meio da relação com outro, a qual vai permitindo que se veja como separado da mãe, diferenciando o "eu” do "não-eu” (PITANGUY, 2007). Essa interação afetiva significativa ao desenvolvimento emocional é possibilitada quando a mãe apresenta maturidade emocional suficiente que permita a existência singular do bebê.

Observa-se, também em Winnicott, a desvinculação da concepção passiva de sujeito. O psicanalista concebe o bebê como uma figura ativa e participativa, uma vez que ele comporta um potencial inato direcionado à sua continuidade de ser e de se desenvolver. A partir desses pressupostos, Aiello-Vaisberg (2009) coloca que, no princípio do existir do bebê não haveria propriamente um indivíduo, mas um "campo experiencial”, constituído pela díade mãe-bebê. O sujeito, desde sua incipiência, deve ser concebido como existente e atuante, compreendendo, assim, o psiquismo como emergente de experiências relacionais.

"No processo de vir a ser um indivíduo, o bebê (e a mãe) 'juntam isto e aquilo, aqui e ali'. A experiência primitiva do self é fragmentada e, ao mesmo tempo (com a ajuda da mãe) 'reunida' de forma a permitir que o bebê tenha a experiência de self, repetidas vezes, para ficar coeso num lugar.” (OGDEN, 2002, p.739)

A princípio, o ego do bebê encontra-se em um estado não integrado, cuja unidade precisa ser conquistada por meio das relações objetais estabelecidas nos estágios primitivos do desenvolvimento humano (WINNICOTT, 1962c/ 1983). 
Conforme Winnicott (1956/2000), o bebê no início da vida se manifesta no mundo por meio de sua motilidade, a qual se refere ao potencial existencial do ser humano e se constitui pela vitalidade no sentido da vida.

Desde sua origem, o ser humano comporta potencialidades singulares e inatas de vir a ser no mundo (SAFRA, 2004). A singularidade do bebê é reiterada por Naffah Neto, ao afirmar que anterior à constituição de um si-mesmo integrado, o lactente já manifesta um estilo próprio de estar no mundo, "ou seja, o 'próprio' precede o 'si', designado pela maneira peculiar e única que cada bebê possui de aglutinar uma herança biológica e articulá-la de forma viva perante aquele ambiente singular que lhe dá sustentação" (NAFFAH NETO, 2005, p.439).

A comunicação estruturante que se dá no interjogo das primeiras experiências subjetivas ocorre, portanto, por meio dessas solicitações corporais espontâneas do bebê, às quais a devotada mãe, de forma suficientemente sensível e constante, atende, acolhe e as interpreta ao bebê (OGDEN, 1996; PIEROTTI, LEVY \& ZORNIG, 2010; ZORNIG, 2010; WINNICOTT, 1965a/2011). A figura materna, por meio do cuidar, "investe e significa esteticamente a corporeidade e o ser da criança”" (SAFRA, 1998, p.19), permitindo a esta, por meio deste significativo encontro, a aquisição de uma unidade corporal e a integração das experiências sensoriais.

"Ela [mãe suficientemente boa] protege o bebê de sustos e coincidências [...], tentando manter a situação física e emocional suficientemente simples para que o bebê consiga entender, e ainda assim rica o bastante para atender às suas crescentes capacidades. Ela fornece continuidade. Por acreditar que o bebê é um ser humano por direito próprio, ela não apressa o seu desenvolvimento, e assim capacita o bebê a apropriar-se do tempo, a ter o sentimento de um existir interno e pessoal." (WINNICOTT, 1948/2000, p.237-238)

Ao destacar o jogo lúdico mãe-bebê, Winnicott identifica a sutileza da comunicação mútua e silenciosa que permeia a relação intersubjetiva no processo de constituição psíquica do bebê, na qual o brincar possibilita a construção íntegra da existência experiencial do ser humano (WINNICOTT, 1971/1975). Evidencia-se a importância atribuída ao brincar espontâneo entre mãe e filho, como possibilidade de um contanto íntimo, constitutivo e criativo.

A compreensão psicanalítica sobre o processo de constituição subjetiva, além de enfatizar a importância dos cuidados maternos iniciais e as implicações das relações inter-humanas, considera também a forma como o bebê participa e responde a este ambiente. Por se tratar de uma dupla mãe-bebê, ambos devem ser reconhecidos em suas especificidades, uma vez que o bebê enquanto um ser 
ativo, dotado de características singulares e sensível ao ambiente, pode facilitar ou dificultar algumas situações, assim como o ambiente.

\section{A PERSPECTIVA WINNICOTTIANA SOBRE A CONSTITUIÇÃO DA SAÚDE}

A compreensão winnicottiana relaciona a saúde psíquica à possibilidade do sujeito de se sentir verdadeiramente vivo, real e capaz do gesto espontâneo. Entende-se, portanto, que o indivíduo saudável é aquele que se encontra integrado, vivendo no interior da psique, habitando o próprio corpo e sentindo que o mundo é real (WINNICOTT, 1945/2000). De acordo com Winnicott (1958/2011), a saúde não se caracteriza pela ausência de sintomas ou doenças, mas pela correspondência entre a maturidade e a idade do indivíduo, de modo que a "continuidade de ser significa saúde” (p.148).

Winnicott parte da premissa de uma concepção de desenvolvimento saudável, em que, perante as condições ambientais adequadas, o indivíduo tende a seguir rumo ao amadurecimento pessoal saudável e à integração da personalidade (BUSNARDO, 2012). Sob esta perspectiva, todo ser humano está de modo contínuo crescendo e se desenvolvendo a partir dos fatores hereditários, inserido em um ambiente, evoluindo da dependência absoluta à independência relativa. Para o autor, "a integração da personalidade não é alcançada num determinado dia ou numa determinada época. Ela vai e vêm, e mesmo quando alcançada em alto grau pode ser perdida devido a uma situação ambiental adversa” (WINNICOTT, 1950-1955/2000, p.289). Esse processo dinâmico e complexo é que leva à possibilidade de uma existência saudável.

O paradoxo winnicottiano sobre o relacionamento mãe-bebê revela a magnitude e as implicações desse encontro singular para o estabelecimento da saúde mental. Sua concepção de saúde apresenta-se indissociavelmente atrelada aos processos do amadurecimento humano, na medida em que é necessário um espaço intersubjetivo favorável para a constituição e sustentação existencial. Conforme Winnicott (1948/2000, p.236), “a saúde mental do ser humano tem suas bases assentadas na primeira infância pela mãe, que fornece um meio ambiente onde os processos complexos mais essenciais ao eu do bebê conseguem completar-se".

Winnicott (1962b/1983) enfatiza a necessidade da existência de um cuidador como condição primordial para a constituição psíquica e, portanto, para o estabelecimento da saúde mental. O ambiente tem, portanto, função facilitadora para a integração psíquica do bebê. Entretanto, para o bebê entrar no mundo e se sentir vivo e real, é necessário, por meio de seu próprio gesto espontâneo, a transformação do mundo em si mesmo, para que possa dele se apropriar e compartilhá-lo (SAFRA, 2005). 
"Para que a ilusão se dê na mente do bebê, um ser humano precisa dar-se ao trabalho permanente de trazer o mundo para ele num formato compreensível e de um modo limitado, adequado às suas necessidades. Por esta razão não é possível a um bebê existir sozinho física ou psicologicamente, e de fato é preciso que uma pessoa específica cuide dele no início.” (WINNICOTT, 1945/2000, p.229)

Esse fenômeno de encontrar-criar possibilita a experiência inaugural de "ilusão de onipotência", na medida em que por meio de uma suposta sensação de onipotência, o bebê encontra o que necessitava. Segundo Winnicott (1988/1990), “sabemos que o mundo estava lá antes do bebê, mas o bebê não sabe disso, e no início tem a ilusão de que o que ele encontra foi por ele criado” (p.131). Entretanto, ressalta que a capacidade criativa vincula-se à presença de cuidados maternos suficientemente adequados disponibilizados ao bebê. Segundo Vieira (2010), a constituição de um sentido de existência está relacionada à capacidade do sujeito de integrar as experiências no campo da ilusão. Dessa forma, a experiência de ilusão estabelece as bases para o desenvolvimento criativo e permite ao sujeito transitar num espaço transicional, entre o interno e o externo (ZORNIG, MORSH \& BRAGA, 2004).

O processo de amadurecimento pessoal subjaz ao estabelecimento da saúde, posto que, a conquista desta, se constitui no decorrer do trajeto do desenvolvimento humano. Assim, a concepção winnicottiana de saúde admite em seu bojo uma inerente flexibilidade, pois, o processo de amadurecimento individual compreende sucessivas conquistas e perdas (DIAS, 2002). Segundo Safra (2005), a inscrição, a simbolização e a evolução dos elementos do si-mesmo podem vir a ocorrer ou não, de acordo com a qualidade do encontro com o outro. Assim, a constituição do si-mesmo não se estabelece de forma definitiva, mas em ciclos. Sob esse prisma, a concepção de saúde possui uma propriedade temporal, uma vez que o fenômeno da aquisição e da evolução dos aspectos do si-mesmo está em contínuo devir e contempla ampla gama de possibilidades quanto à retomada do amadurecimento pessoal.

\section{DIMENSÕES INIMAGINÁVEIS DO SOFRIMENTO EMOCIONAL HUMANO}

A teoria winnicottiana sobre o sofrimento psíquico desvincula-se do modelo metapsicológico freudiano orientado pelas pulsões e propõe uma perspectiva psicopatológica relacional sustentada pelo reconhecimento dos vínculos inter-humanos e da singularidade individual (AIELLO-VAISBERG \& MEDEIROS, 2010; FULGENCIO, 2011; LOPARIC, 2006). Para Aiello-Vaisberg e Medeiros, “a visão relacional busca posicionar a psicopatologia num campo vincular, compreendendo o adoecimento como fenômeno que acontece na intersubjetividade” (2010, p.99). 
Segundo Lescovar (2008), o adoecimento do ser humano ocorre quando o ambiente não possibilita a concretização das potencialidades individuais, ocasionando um congelamento do processo de amadurecimento pessoal. As falhas do ambiente podem levar o indivíduo a vivenciar experiências traumáticas que acarretam reações que podem conduzi-lo à interrupção do estabelecimento do self, instaurando um processo de ruptura da personalidade do indivíduo. Em decorrência, podem despertar a insegurança em relação ao meio, bem como ansiedades muitíssimo primitivas (WINNICOTT, 1959-1964/1983).

À luz das contribuições winnicottianas, compreende-se que o campo do sofrimento e adoecimento humano configura-se a partir de adiamentos, distorções, regressões e confusões nos estágios iniciais do desenvolvimento, do conjunto ambiente-indivíduo (WINNICOTT, 1952/2000). A imprevisibilidade e a intrusão ambiental podem mobilizar inúmeras manobras defensivas e produzir variados graus de distorção no desenvolvimento pessoal que resultam na impossibilidade de se sentir vivo e real.

A impossibilidade da sua constituição, devido à privação de uma significativa experiência de vinculação, remete o indivíduo a um intenso desamparo emocional. Quando o ambiente humano, no estágio primitivo do desenvolvimento individual, não for suficientemente capaz de prover os cuidados vitais, desamparando o bebê por períodos muito longos, este, ainda desprovido de maturidade suficiente para lidar com seu ambiente, poderá entrar em contato com as agonias impensáveis, tal como denominadas por Winnicott (1962c/1983).

De acordo com Naffah Neto (2007), a fim de se proteger das sensações de ameaça à existência pessoal do eu, o bebê irá interromper sua continuidade de ser, reagindo frente a este ambiente privador. Esse autor afirma que "romper a continuidade de ser do bebê significa, pois, privá-lo de uma parte do seu espaço vital" (2005, p.443). O resultado mais marcante das falhas ambientais é um sentimento permanente de aniquilamento que toma conta do bebê, uma vez que a continuidade de sua existência é de maneira imprevista interrompida (LOPARIC, 1996). Portanto, perante a privação ambiental e emocional, o lactente, à mercê de sua própria sorte, é forçado a criar defesas. Ele, então, adoece, na medida em que, ao se defender desse meio intrusivo, precisa interromper sua continuidade de ser.

Segundo Winnicott (1988/1990), quando o bebê é apresentado ao mundo de forma abrupta e confusa, a capacidade de encontrar-criar o mundo não se estabelece, pois o lactente não possui recursos suficientes para lidar com a realidade externa devido à sua imaturidade (UNGIER, 2010). Logo, a aquisição da capacidade de ilusão não se estabelece ou se revela extremamente frágil, e, assim, o bebê fica à mercê de experiências aflitivas de frustração e desilusão. 
De acordo com Ogden (1996), o colapso no campo das relações intersubjetivas adquire proporções imensas que se estende sob a frágil e incipiente constituição subjetiva do ser que está por vir. O fracasso no relacionamento mãe-bebê pode implicar a desconexão do indivíduo não só com a mãe, mas com “o próprio tecido da matriz interpessoal humana” (p.163), de modo que essa forma primitiva de isolamento corresponde à proteção da experiência de ainda estar vivo.

Safra (2004) afirma que quando o bebê não tem a oportunidade de experienciar uma relação humana significativa nos primórdios do seu desenvolvimento, o início de sua possibilidade de ser fica suspensa. E, nesses casos, nos quais não foi possível ocorrer a constituição psíquica, incidem formas de adoecimento primitivas, designadas pelo autor como "fraturas éticas originárias".

O paradigma winnicottiano referente à etiologia e à classificação dos distúrbios psíquicos contribuiu de forma original para o pensamento psicanalítico. A experiência de sofrimento psíquico varia de acordo com a existência de um si-mesmo, constituído pela impossibilidade de sua existência, ou ainda, pela instauração de um falso si-mesmo. A experiência agônica decorrente dos estágios primitivos do processo de amadurecimento pessoal revela a inexistência de um si-mesmo integrado, cujo cerne do transtorno é psicótico.

A origem das perturbações emocionais primitivas reconhecidas e classificadas como psicoses encontra-se nas possíveis falhas ambientais ocorridas numa fase inicial do desenvolvimento do conjunto ambiente-indivíduo (WINNICOTT, 1963a/1983). A natureza das defesas mobilizadas nas psicoses, frente a este ambiente privador, paralisa a tendência inata ao amadurecimento pessoal, impedindo a possibilidade autêntica do acontecer humano. Dias (2003) expõe que a natureza das defesas mobilizadas nas psicoses paralisa a tendência inata ao amadurecimento pessoal, impedindo assim a possibilidade autêntica do acontecer humano.

Winnicott (1954/2000) concebe a "doença psicótica como uma organização defensiva cujo objetivo é proteger o verdadeiro eu” (p.384). A exposição prematura do lactente às recorrentes ansiedades inimagináveis pode levá-lo à formação de um falso self, que tem por finalidade preservar a continuidade do ser, no self verdadeiro ameaçado. De acordo com Vilete (2002), "este seria o caminho para o estabelecimento de patologias primitivas, como as psicoses, os quadros esquizoides, o falso self e as personalidades borderlines” (p.841).

O sofrimento psíquico abordado nesse trabalho compreende aquele que excede a capacidade de suportabilidade humana individual, e é originário de experiências traumáticas primitivas que ocorreram em um momento em que o indivíduo imaturo ainda não possuía recursos psíquicos suficientes. A ausência de recursos para lidar com as recorrentes falhas ambientais pode levá-lo a uma 
vivência confusa, ou, ainda, à impossibilidade de gestar seu próprio nascimento psíquico.

Torna-se imprescindível a diferenciação da dimensão do sofrimento emocional à qual as perturbações psíquicas precoces estão sujeitas. Segundo o pensamento winnicottiano, a agonia subjacente a essas perturbações mais graves é inimaginável, ou seja, impensável (WINNICOTT, 1963b/1994). Trata-se de uma angústia primitiva de aniquilamento, que está associada a sofrimentos máximos de qualidade e intensidade psicótica (WINNICOTT, 1960/1983). Esse sofrimento não possui uma representação mental, pois se trata de uma dor intolerável, da ordem do incompreensível, que conduz o ser imaturo a um plano intempestivo de agonias, cujas sensações referem-se às diversas ameaças ao sentimento de existir, tais como: sensações de desintegração, temor da perda do contato com a realidade e o pânico do desalojamento do próprio corpo.

“Exemplos paradigmáticos de dores desse tipo são as 'agonias impensáveis' de Winnicott, 'impensáveis' por serem anteriores a qualquer representação mental, e 'agonias' porque implicam a luta pela continuidade do ser. Esse sofrimento é 'primitivo', [...], por ter sua origem no relacionamento a dois, prévio à existência de qualquer estrutura representacional no bebê humano.” (LOPARIC, 2001, p.48-49)

Segundo Safra (2004), os indivíduos que não alcançaram a constituição de um si-mesmo integral e singular, vivem em um constante estado de agonia. São indivíduos que nem alcançaram a possibilidade de sofrer, pois, por serem insuficientemente maduros não possuem recursos para a representação do sofrimento. O autor afirma que, para haver a percepção e o reconhecimento do próprio sofrimento, é necessária a possibilidade de sua destinação e, ressalta que "há sempre no desespero vivido pelo indivíduo a expectativa de um encontro que transforme o insuportável em uma experiência que possa vir a ter um sentido e possa vir a ser um sofrimento" (p.70).

Para o pensamento psicanalítico winnicottiano, as experiências de ansiedades inimagináveis variam e são caracterizadas de acordo com o nível de integração que o indivíduo preserva frente às catastróficas falhas ambientais. Assim, quando nenhuma integração é mantida pode ocorrer a desintegração do ser e a invulnerabilidade é alcançada. Em outros casos, em que os indivíduos conseguem manter certa integração frente às vivências de aniquilamento, podem desenvolver um estado patológico caótico, em que estão de forma constante preocupados com a recorrência da ameaça e em estado de agonias intermináveis. E, ainda, existem ocasiões em que a integração é preservada e os indivíduos conseguem viver de forma espontânea e o sofrimento manifestado comporta problemáticas aflitivas próprias do viver e da existência (WINNICOTT, 1965b/1994). 
A fim de compreender a estruturação psíquica, diferenciar as causas implícitas do transtorno psíquico - alterações físicas ou decorrentes de falhas ambientais —, e propor manejos clínicos adequados ao paciente torna-se, portanto, relevante uma investigação cuidadosa da trajetória de vida do indivíduo.

A partir desses diferenciais clínicos, Winnicott (1962c/1983) propõe que os objetivos do tratamento psicanalítico a indivíduos que possuem perturbações psíquicas precoces devem ser orientados ao suprimento das falhas ambientais iniciais, a fim de oferecer as condições essenciais para a retomada do processo de amadurecimento pessoal. Esse enquadramento clínico pode promover a retomada da evolução do si-mesmo e, portanto, a continuidade existencial do ser humano.

Winnicott (1963c/1983) não desconsidera a presença de fatores congênitos, hereditários ou de alterações físicas na constituição dos transtornos psíquicos, entretanto, salienta que as causas não se limitam de modo simples e exclusivo a essa modalidade biológica. Declara que os distúrbios psiquiátricos estão, muitas vezes, associados a fatores patológicos hereditários. Mas ratifica que, de modo geral, esses fatores são de ordem ambiental, ou seja, são falhas graves que incidem na relação intersubjetiva entre mãe-bebê, durante os estágios primitivos da constituição psíquica.

A investigação realizada por Winnicott, centra-se em sua essência no campo das possibilidades da real existência do indivíduo em meio às relações inter-humanas. Segundo o autor, os distúrbios mentais não são doenças, mas conciliações entre a imaturidade do indivíduo e as condições ambientais reais, que impossibilitam a capacidade de viver.

A compreensão winnicottiana sobre o adoecimento psíquico rompe com a classificação reducionista do sofrimento humano em estritas categorias psicopatológicas. Contrapõe-se ao modelo estrutural e preditivo do sofrimento psíquico, uma vez que as concepções de constituição psíquica, de adoecimento e, também de cura, perpassam o âmbito da intersubjetividade. Ao considerar que a constituição da saúde emocional do indivíduo se dá por meio de arranjos e rearranjos possíveis, coloca em questão, ainda, o modelo determinista de causa e efeito, no sentido fatalista de uma predição psicopatológica. Os alicerces da saúde mental podem advir de uma infância vivida de forma satisfatória. Entretanto, isso não assegura a sustentação definitiva de um posicionamento existencial integral (AIELLO-VAISBERG \& BOTELHO-BORGES, 2011).

A necessidade de um ambiente adequado e favorável para o desenvolvimento das potencialidades do vir a ser do bebê é ressaltada na concepção winnicottiana. Os fatores ambientais são considerados imprescindíveis para o estabelecimento e a retomada da saúde pelo indivíduo, a despeito da possibilidade de a criança poder vir a encontrar meios de crescer de forma minimamente saudável, a partir de seu próprio potencial espontâneo, apesar das falhas ambientais. 
Por meio dos pressupostos psicanalíticos apresentados, compreende-se que a constituição psíquica e também a sua impossibilidade constitutiva advém, em essência, do campo da intersubjetividade. A constituição e a sustentação emocional decorrem da legitimação de um cuidador devotado, que reconheça o bebê em sua singularidade e possibilite sua inscrição no mundo. No estágio primitivo do seu desenvolvimento, o ser humano está na incumbência de ser, e sua existência transita nesse momento entre o não-ser e o ser. De acordo com a teoria winnicottiana é possível afirmar que a ausência de uma significativa experiência vincular inter-humana nos períodos iniciais da vida, pode levar o imaturo ser a mobilizar defesas contra a realidade com a qual ele ainda não tem condições de lidar. Ao se tornar assustadoramente invasivo, o ambiente promove constantes ameaças à existência do indivíduo, podendo levá-lo a interromper o seu processo de amadurecimento pessoal, pela necessidade de manter o verdadeiro si-mesmo protegido, à espera de melhores condições ambientais que permitam a retomada da continuidade do ser.

\section{CONSIDERAÇÕES FINAIS}

Abordou-se a vivência de sofrimento emocional que se apresenta à clínica contemporânea à luz das contribuições psicanalíticas winnicottianas. Esse sofrimento pode ser compreendido como derivado da impossibilidade do sujeito em elaborar experiências traumáticas primitivas em seu processo de desenvolvimento, experiências estas, por sua magnitude, comprometem a emergência ou o nascimento psíquico. Evidencia-se a possibilidade da emergência de um si-mesmo real e espontâneo como relacionada à presença constante e afetiva de um ambiente facilitador. Conclui-se que o paradigma winnicottiano do adoecimento psíquico contribuiu de forma original com a concepção psicanalítica no campo da saúde mental, possibilitando propostas preventivas e manejos clínicos diferenciados a partir de uma perspectiva psicopatológica relacional. Entretanto, ao se referir à etiologia e à classificação dos transtornos emocionais, Winnicott adota uma postura cautelosa, e adverte quanto à atitude equivocada e precipitada dos profissionais de Saúde em atribuir aos distúrbios mentais um caráter deficitário e em estabelecer, de modo estrito, relações de causalidade entre as manifestações do sofrimento psíquico e as relações vinculares, admitindo necessária a busca por vínculos e possibilidades alternativas para o vir a ser. 


\section{REFERẼNCIAS}

AIELLO-VAISBERG, T.M.J. (2009) Subjetividade e alteridade: considerações sobre os fundamentos de uma clínica grupal na perspectiva winnicottiana. Revista da SPAGESP - Sociedade de Psicoterapias Analíticas Grupais do Estado de São Paulo, v.10, n.1, p.29-40.

; MEDEIROS, C. (2010) Acordes do sofrimento humano. Contextos Clínicos, São Leopoldo, v.3, n.2, 97-105.

; BOTELHO-BORGES, A.A. (2011) Desenvolvimento de capaci-

dades e gestualidade espontânea. Paidéia, Ribeirão Preto, v.21, n.49, p.257-262.

BUSNARDO, J.O.M. (2012) “Contribuições de D. W. Winnicott para o campo da nosografia psicanalítica”. Dissertação de Mestrado, Programa de Pós-Graduação em Psicologia, Pontifícia Universidade Católica de Campinas, Campinas.

COELHO JUNIOR, N.; FIGUEIREDO, L.C. (2004) Figuras da Intersubjetividade na constituição subjetiva: dimensões da alteridade. Interações, São Paulo, v.IX, n.17, p.9-28.

DIAS, E.O. (2002) A trajetória intelectual de Winnicott. Natureza Humana, Revista Internacional de Filosofia e Práticas Psicoterápicas, São Paulo, v.4, n.1, p.111-156. Imago.

. (2003) A teoria do amadurecimento de D.W. Winnicott. Rio de Janeiro:

FIGUEIREDO, L. C. (2005) A questão do sentido, a intersubjetividade e as teorias das relações de objeto. Revista Brasileira de Psicanálise, São Paulo, v.39, n.4, p.79-88.

FULGENCIO, L. (2011) A importância da noção de experiência no pensamento de D. W. Winnicott. Estudos de Psicologia, Campinas, v.28, n.1, p.57-64.

KHAN, M.M. (1978/2000) “Introdução”, in WINNICOTT, D.W. Da pediatria à psicanálise: obras escolhidas. Rio de Janeiro: Imago.

LESCOVAR, G.Z. (2008) As consultas terapêuticas como possibilidade de atenção intensiva em saúde mental. Mudanças - Psicologia da Saúde, São Paulo, v.16, n.1, p.21-26.

LISONDO, A. (2004) A subjetividade é construída na intersubjetividade. Trabalho apresentado na V Jornada de Psicanálise de Aracaju.

LOPARIC, Z. (1996) “Édipo pós-Freud”. Trabalho apresentado no I Encontro do Grupo de Estudos de Psicanálise de Ribeirão Preto, Ribeirão Preto, SP.

(2001) Esboço do paradigma winnicottiano. Cadernos de História e Filosofia da Ciência, v.11, n.2, p.7-58.

(2006) De Freud a Winnicott: aspectos de uma mudança paradigmática. Natureza Humana, Revista Internacional de Filosofia e Práticas Psicoterápicas, v.8, n.1, 21-47, Especial.

NAFFAH NETO, A. (2005) Winnicott: uma psicanálise da experiência humana em seu devir próprio. Natureza humana. Revista Internacional de Filosofia e Práticas Psicoterápicas, São Paulo, v.7, n.2, p.433-454. 
(2007) A problemática do falso self em pacientes de tipo borderline: revisitando Winnicott. Revista Brasileira de Psicanálise, v.41, n.4, p.77-88.

OGDEN, T.H. (1996) Os sujeitos da psicanálise. São Paulo: Casa do Psicólogo. (2002) Lendo Winnicott. Revista Brasileira de Psicanálise, São Paulo, v.36, n.4, p.737-755.

PIEROTTI, M.M. de S.; LEVY, L.; ZORNIG, S. (2010) O manhês: costurando laços. Estilos da Clínica, São Paulo, v.15, n.2, p.420-433.

PITANGUY, L. (2007) “Thomas Ogden: as dimensões da experiência”, in PINTO, M.C.O. (Org.), Livro de Ouro da Psicanálise. Rio de Janeiro: Ediouro.

SAFRA, G. (1998) A transmissão do self no grupo familiar. Interações, São Paulo, v.III, n.6, p.17-21.

. (2004) A po-ética na clínica contemporânea. Aparecida (SP): Ideias \& Letras.

(2005) A face estética do self: teoria e clínica. Aparecida (SP): Ideias \& Letras: São Paulo: Unimarco.

SANTOS, E.S. (2006) O acontecer humano: alguns apontamentos. Winnicott e-prints, v.1, n.1, 2006. Disponível em http://pepsic.bvsalud.org/ scielo.php?script $=$ sci_arttext\&pid=S1679-432X2006000100002\&lng $=$ pt\&nrm=iso. Acesso em: 03/01/2011.

UNGIER, A. (2010) Para além do som e da fúria. Revista Brasileira de Psicanálise, São Paulo, v.44, n.2, p.91-99.

VIEIRA, M.C.S. (2010) "Reflexões possíveis: o olhar de Winnicott e Lacan para a constituição subjetiva”. Dissertação de Mestrado, Programa de Pós-Graduação em Psicologia, Instituto de Psicologia da Universidade de São Paulo, São Paulo.

VILETE, E.P.(2002) Regressão no processo analítico: a visão de Winnicott. Revista Brasileira de Psicanálise, São Paulo, v.36, n.4, p.835-843.

ZORNIG, S. (2000) "Psicanálise com crianças: entre a origem e o originário”. in A criança e o infantil em psicanálise. São Paulo: Escuta.

; MORSH, D.S.; BRAGA, N.A. (2004) Os tempos da prematuridade. Revista Latino-americana de Psicopatologia Fundamental, São Paulo, v.VII, n.4, p.135-143.

(2010) Reflexões sobre uma ética do cuidado na primeira infância. Primórdios-CPRJ, Rio de Janeiro, v.1, n.1, p.15-26.

WINNICOTT, D.W. (2000) Da pediatria à psicanálise: obras escolhidas. Trad. D. Bogomoletz. Rio de Janeiro: Imago.

(1945) "O desenvolvimento emocional primitivo", p.218-232.

(1948) “Pediatria e psicanálise”, p.233-253.

(1950-1955) "A agressividade em relação ao desenvolvimento emocional”, p.288-304.

(1952) "Psicoses e cuidados maternos", p.305-315

(1954) “Aspectos clínicos e metapsicológicos da regressão no contexto analítico”, p.374-392.

(1956) “A preocupação materna primária”, p.399-405.

(2011) A família e o desenvolvimento individual. Trad.I. C.S. Ortiz. São

Paulo: Martins Fontes.

(1958) “Definição teórica do campo da psiquiatria infantil”, p.141-152. 
(1965a) “O relacionamento inicial entre uma mãe e seu bebê”, p.21-28. (1983). O ambiente e os processos de maturação: estudos sobre a teoria do desenvolvimento emocional. Trad. M. B. Cipolla. Porto Alegre: Artmed.

(1959-1964). "Classificação: existe uma contribuição psicanalítica à classificação psiquiátrica?”, p.114-127.

(1960). “Teoria do relacionamento paterno-infantil”, p.38-54.

(1962b) "Provisão para a criança na saúde e na crise”, p.62-69.

(1962c) “Os objetivos do tratamento psicanalítico”, p.152-155.

(1963a) "Distúrbios psiquiátricos e processos de maturação infantil”, p.207-217.

(1963c) “Os doentes mentais na prática clínica”, p.196-206.

; SHEPPHERD, R.; DAVIS, M. (Orgs.). (1994) Explorações psica-

nalíticas: D.W. Winnicott. (J.O. de A. Abreu, Trad.). Porto Alegre: Artes Médicas.

(1963b) "O medo do colapso", p.70-76.

(1965b) "Psicologia da loucura: uma contribuição da psicanálise”, p.94-101.

(1968/2002). “A comunicação entre o bebê e a mãe e entre a mãe e o bebê: convergências e divergências”. Trad. J.L. Camargo, in Os bebês e suas mães. São Paulo: Martins Fontes. p.79-92.

(1971/1975). "O brincar: a atividade criativa e a busca do eu (Self)" in O brincar e a realidade. Trad. J.O. de A. Abreu \& V. Nobre. Rio de Janeiro: Imago. p. 79-93.

. (1988/1990) Natureza humana. Trad. D. Bogomoletz. Rio de Janeiro: Imago.

Heloisa Aguetoni Cambuí

heloisacambui@yahoo.com.br

Carmen Maria Bueno Neme

cmneme@gmail.com

Jorge Luís Ferreira Abrão

abrao@assis.unesp.br 
